\title{
Central and peripheral airway/alveolar sites of exhaled nitric oxide in acute asthma
}

\author{
Arthur F Gelb, ${ }^{1}$ Steven C George, ${ }^{2}$ Philip E Silkoff, ${ }^{3}$ Anita Krishnan, ${ }^{4}$ Christine Fraser, \\ Colleen Flynn Taylor, ${ }^{4}$ Chris M Shinar, ${ }^{5}$ Tamara Maginot $^{4}$
}

${ }^{1}$ Pulmonary Division

Department of Medicine, Lakewood Regional Medical Center, and Geffen School of Medicine, University of California at Los Angeles Medical Center, Lakewood, California, USA

${ }^{2}$ Department of Biomedical Engineering and Chemical Engineering and Materials Science, University of California, Irvine, USA

${ }^{3}$ Drexel University School of Medicine, Philadelphia, Pennsylvania, USA

${ }^{4}$ Lakewood Regional Medical Center, Lakewood, California, USA

${ }^{5}$ Department of Performance Improvement and Patient Safety, Orange Coast Memorial Medical Center, Fountain Valley, California, USA

\section{Correspondence to}

Professor Arthur F Gelb, 3650 E. South St., Suite 308 Lakewood, CA 90712, USA;

afgelb@msn.com

AK, CF, CFT and TM are independent research contractors.

Received 6 December 2009 Accepted 18 April 2010

\section{ABSTRACT \\ Introduction Central airway nitric oxide flux $\left(\mathrm{J}_{\text {awno }}\right)$ and peripheral airway/alveolar nitric oxide concentration $\left(\mathrm{C}_{\mathrm{ANO}}\right)$ during asthma exacerbation has not been investigated after correction for axial NO back-diffusion.} Methods After measuring exhaled NO (fraction of exhaled nitric oxide ( $\left.\mathrm{F}_{\mathrm{E}} \mathrm{NO}\right)$; ppb) at 50, 100, 150 and $200 \mathrm{ml} / \mathrm{s}, \mathrm{J}_{\text {awNO }}(\mathrm{nl} / \mathrm{s})$ and $\mathrm{C}_{\text {ANO }}(\mathrm{ppb})$ were calculated using the two-compartment model and corrected for axial NO back-diffusion. Fifteen (8 males), non-smoking, patients with moderate-to-severe treated (inhaled corticosteroid (ICS) and inhaled long-acting $\beta_{2}$-agonist (LABA)) asthma, age $57 \pm 13$ years (mean $\pm S D$ ), were studied at baseline, during exacerbation prior to oral corticosteroid, and during recovery after an 8 day tapering prednisone course. Based on earlier asthma studies without correction, it was hypothesised that with correction for $\mathrm{NO}$ axial back-diffusion, the incidence of abnormal $\mathrm{J}^{\prime}$ awNo and $\mathrm{C}_{\text {ANO }}$ at baseline and after exacerbation would be $\geq 30 \%$ in 15 patients with asthma with $80 \%$ power.

Results At baseline when clinically stable, after $180 \mu \mathrm{g}$ of albuterol, forced expiratory volume in $1 \mathrm{~s}$ (FEV was $78 \pm 26 \%$ predicted $(p=0.009)$ with increased $F_{E} N 0$ at $50 \mathrm{ml} / \mathrm{s}(p=0.01)$ and $\mathrm{J}^{\prime}$ awno $(p=0.02)$, but $\mathrm{C}_{\text {ANO }}$ was normal compared with the controls. During exacerbation $\mathrm{FEV}_{1}$ (litres) was $57 \pm 20 \%$ predicted $(p=0.02)$, with increased $\mathrm{F}_{\mathrm{E}} \mathrm{NO}$ at $50 \mathrm{ml} / \mathrm{s}(\mathrm{p}=0.01)$ and $\mathrm{J}_{\text {awNO }}$ $(p=0.004)$, but $C_{\text {ANO }}$ was normal. Recovery results were similar to baseline. Two of 15 patients with asthma always had normal exhaled NO gas exchange.

Conclusions The central airways were the major site of abnormal NO flux in 13 of 15 patients with moderate-severe asthma when stable and during exacerbation and could be easily detected with abnormal $\mathrm{F}_{\mathrm{E}} \mathrm{NO}$ at $50 \mathrm{ml} / \mathrm{s}$. $\mathrm{C}_{\mathrm{ANO}}$ was normal.

Clinical trial number NCT00576069.

Measurement of the fraction of exhaled nitric oxide $\left(\mathrm{F}_{\mathrm{E}} \mathrm{NO}\right.$; ppb) is a relatively simple, reproducible and non-invasive test for monitoring airway inflammation. ${ }^{1}$ Increased $\mathrm{F}_{\mathrm{E}} \mathrm{NO}$ in asthma is accepted as a surrogate for predominantly eosinophilic-mediated inflammation in central airways and increased response to inhaled corticosteroid (ICS) ${ }^{1-5}$ The currently accepted method of measuring $\mathrm{F}_{\mathrm{E}} \mathrm{NO}$ at a single constant expiratory flow rate, usually $50 \mathrm{ml} / \mathrm{s}$, is incapable of separating out whether the source of increased NO production is the large central airways or the peripheral small airway/ alveolar site, or both. ${ }^{6}$ However, increased $\mathrm{F}_{\mathrm{E}} \mathrm{NO}$ predominantly reflects large central airways. Therefore, several investigators have developed newer techniques to discriminate $\mathrm{NO}$ gas exchange between large central airways and peripheral smaller airways/alveolar compartments. ${ }^{7-12}$

Using a two-compartment model developed by Tsoukias and George, ${ }^{11}$ central airway NO flux and peripheral airway/alveolar concentration can be estimated by measuring $\mathrm{F}_{\mathrm{E}} \mathrm{NO}$ at multiple expiratory flows and plotting $\mathrm{NO}$ output versus expiratory flow. The slope of the linear regression line between $\mathrm{NO}$ output versus flow reflects the peripheral airway/alveolar $\mathrm{NO}$ concentration ( $\mathrm{C}_{\mathrm{ANO}}$; ppb), whereas the $y$-intercept reflects central airway NO flux J' awNo (nl/s). ${ }^{11} \mathrm{We}^{13} 14$ and others $^{8} 12{ }^{15-21}$ using this mode ${ }^{11}$ have previously reported $\mathrm{NO}$ gas exchange in central as well as peripheral airway/alveolar sites in those with mild $^{8} 1215 \quad 18-21$ and moderate-severe 81314161720 clinically stable asthma. However, two groups independently ${ }^{12} 22$ have also demonstrated, both experimentally and theoretically, axial back-diffusion of NO from proximal to peripheral airway/ alveoli, against the direction of exhalation. Furthermore, this may contaminate peripheral airway/alveolar levels, leading to an underestimation of central airway $\mathrm{NO}$ flux and an overestimation of peripheral airway/alveolar $\mathrm{NO}$ levels. Axial NO back-diffusion has not been previously accounted for in those with asthma with abnormal expiratory airflow limitation.

The current prospective outpatient study evaluated $\mathrm{F}_{\mathrm{E}} \mathrm{NO}$ using the two-compartment model before and after correcting for $\mathrm{NO}$ axial backdiffusion $^{12} 22$ in clinically stable, non-smoking, treated patients with asthma with moderatesevere expiratory airflow limitation who were not previously studied. Our goal was to evaluate and partition central airway versus peripheral airway/ alveolar sites of $\mathrm{NO}$ concentration at baseline, during an ensuing spontaneous asthma exacerbation prior to initiation of oral corticosteroid, and following recovery with oral corticosteroid. This has not been investigated previously. Based on our earlier asthma studies ${ }^{13}{ }^{14}$ without correction for axial NO back-diffusion, we hypothesised the incidence of abnormal $\mathrm{J}_{\text {' }}$ awno and $\mathrm{C}_{\mathrm{ANO}}$ at baseline and after exacerbation to be $>30 \%$ in 15 patients with asthma with $80 \%$ power after correction for axial NO back-diffusion.

\section{METHODS \\ Patient selection}

We recruited adult patients with moderate-severe persistent asthma who were on maintenance combination inhaled corticosteroid (ICS)/inhaled long-acting $\beta_{2}$-agonist (LABA), fluticasone propionate $250 \mu \mathrm{g} / \mathrm{salmeterol} 50 \mu \mathrm{g}$ twice a day (F250/ 
S50) (Advair250/50, GlaxoSmithKline, Research Triangle Park, North Carolina, USA) for at least 1 year. Smoking history was $<5$ pack-years and currently all were non-smokers for at least 5 years. All asthma patients were clinically stable for at least 8 weeks and were monitored in our tertiary referral outpatient clinic for $\geq 3$ years. Their asthma symptoms and spirometry were optimal when compared with clinical and spirometric results obtained over the previous $\geq 3$ years. When needed for acute relief, medical treatment included a short-acting inhaled

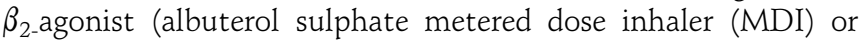
solution) and inhaled antimuscarinic agent ipratropium bromide (Atrovent MDI or solution, Boehringer-Ingelheim Pharmaceuticals, Ridgefield, Connecticut, USA). All those with asthma were off oral corticosteroids, antibiotics and leukotriene-modifying agents for at least 8 weeks before entry into the study. Serum eosinophils and immunoglobulin E ( IgE) were measured only at baseline. All subjects with asthma had demonstrated bronchodilator reversibility within the past 2 years defined as an increase in forced expiratory volume in $1 \mathrm{~s}\left(\mathrm{FEV}_{1}\right) 200 \mathrm{ml}$ and $\geq 12 \%$, $15 \mathrm{~min}$ after $180 \mu \mathrm{g}$ of albuterol via MDI. Our goal was to study prospectively exhaled NO gas exchange in the initial 15 patients with moderate-severe asthma who developed an acute exacerbation requiring oral corticosteroids.

\section{Normal controls}

Normal values for $\mathrm{F}_{\mathrm{E}} \mathrm{NO}$ were obtained from 40 normal subjects (20 males), age $57 \pm 9$ years (mean $\pm \mathrm{SD}$ ), who were asymptomatic, healthy lifelong non-smokers with no history of lung disease and not on any medications. No provocative bronchoconstrictor challenge tests were done on normal subjects. All subjects with asthma and normal subjects studied had given informed consent for participation. This study was approved by both Lakewood Regional Medical Center IRB and Western IRB, Olympia, WA, and registered as NCT00576069.

\section{Measurement of exhaled NO gas exchange}

All subjects abstained from food and coffee for $2 \mathrm{~h}$ and alcohol for $12 \mathrm{~h}$ prior to studies. Exhaled $\mathrm{NO}$ was measured in triplicate prior to spirometry at four separate constant expiratory flow rates: $50,100,150$ and $200 \mathrm{ml} / \mathrm{s}$, and the mean of three values obtained within $10 \%$ of each other was reported using a Sievers NOA 280 chemiluminescence analyser with varying expiratory airflow resistors (GE Analytical Instruments, Boulder, Colorado, USA) as previously described. ${ }^{13} 14$ Furthermore, to avoid nasal $\mathrm{NO}$ contamination, a mouth pressure of $>5 \mathrm{~cm} \mathrm{H}_{2} \mathrm{O}$ was used, as previously recommended. ${ }^{23}$ The $\mathrm{NO}$ analyser was calibrated daily with a known concentration (45 ppm) and before each patient and control subject with NO-free air. The technique of Tsoukias and George ${ }^{11}$ was used to calculate central airway NO maximal flux (J'awnO, $\mathrm{nl} / \mathrm{s}$ ) ( $y$-intercept) and steady state peripheral airway/alveolar NO concentration ( $\mathrm{C}_{\mathrm{ANO}}$, ppb) (slope) using a linear regression line for each subject with a minimum of three expiratory flow rate data points and $r^{2}$ of $\geq 0.9$. Correction was made for potential underestimation of large airway $\mathrm{NO}$ flux due to axial back-diffusion of $\mathrm{NO}$ using the method of Condorelli et $\mathrm{al}^{22}$ by multiplying large airway NO flux J' awno by a factor of 1.7. Furthermore, to adjust for possible spurious overestimation of values for peripheral lung $\mathrm{C}_{\mathrm{ANO}}$, initial uncorrected large airway NO flux J' awNO (nl/s) was divided by a correction factor of 0.53 and subtracted from initial uncorrected small airway/ alveolar $\mathrm{C}_{\mathrm{ANO}}{ }^{22}$ This could yield negative or near zero values for peripheral lung $\mathrm{C}_{\mathrm{ANO}}{ }^{22}$ This correction factor was determined in normal subjects and those with mild asthma using flow rates of $50-250 \mathrm{ml} / \mathrm{s}^{22}$ Investigators responsible for measuring $\mathrm{F}_{\mathrm{E}} \mathrm{NO}$ gas exchange and lung function (CFT, CF and AK) were blinded to the therapeutic intervention. Spirometry and $\mathrm{NO}$ gas exchange were measured at the initiation of the study when subjects with asthma were clinically stable at baseline, and subsequently prior to initiation of oral corticosteroid during exacerbation, and then during recovery immediately after treatment with an 8 day course of tapering oral corticosteroid.

\section{Lung CT studies}

Our goal was to include only patients with asthma without clinically occult significant lung CT-scored emphysema or bronchiectasis. Therefore, all subjects with asthma had highresolution, thin-section scans of the lung obtained using a helical 64 slice multidetector-row CT (Model Sensation 64, Siemens, Malvern, Pennsylvania, USA). Images were obtained at $5 \mathrm{~mm}$ collimation at intervals of $6 \mathrm{~mm}$ using $120 \mathrm{kVp}$ and varying $\mathrm{mA}$ dependent upon patient size. Reconstructured $1 \mathrm{~mm}$ slices were obtained every $9 \mathrm{~mm}$ using a window width of $850 \mathrm{HU}$ and level of $-600 \mathrm{HU}$ with an edge-enhancing algorithm. Images were scored by a radiologist (Mark J Schein) as 0 to 100 , none to worst emphysema, using picture templates which we previously validated using inflated whole lung specimens. ${ }^{24}$

\section{Lung function studies}

When clinically stable at baseline, and during recovery following treatment with oral corticosteroid, subjects with asthma were instructed to continue all their medications, except to withhold MDI albuterol sulphate and/or ipratropium bromide for $6 \mathrm{~h}$, and the LABA DPI (dry powder inhaler) for $24 \mathrm{~h}$ prior to testing. Obviously, during asthma exacerbation, medications were not withheld. Our techniques for measuring spirometry, thoracic gas volumes and airway resistance using plethysmography, and diffusing capacity have been previously published. ${ }^{13} 14$

\section{Protocol: therapeutic intervention with oral corticosteroid}

Once selected for this prospective, single-blind, open label to patient study, patients with asthma were continued on maintenance combination ICS plus inhaled LABA. Concurrent acute relief medications when needed included aerosolised and/or nebulised albuterol sulphate and ipratropium bromide. Definition of asthma exacerbation requiring oral corticosteroids included increasing complaints of cough \pm sputum, chest tightness, wheezing and shortness of breath for $\geq 1$ day. These symptoms were not relieved despite at least three treatments with aerosolised and/or nebulised $2.5 \mathrm{mg}$ albuterol sulphate and $0.5 \mathrm{mg}$ ipratropium bromide within $8 \mathrm{~h}$ and there was a concomitant decrease in $\mathrm{FEV}_{1} \geq 0.3$ litres from baseline. In addition, absence of fever and no acute change on a chest x-ray were required. The decision to initiate oral corticosteroids was determined by the emergency ward or other physician who was initially unaware of the study until the patient with asthma informed the physician, and the Principal Investigator was immediately notified. Asthma exacerbation was treated with an 8 day tapering course of oral prednisone starting with $40 \mathrm{mg}$. Concurrent use of antibiotics was optional and was used in eight of the subjects with asthma. No laboratory study was initiated to definitively determine the aetiology of superimposed acute bronchitis. Measurement of $\mathrm{F}_{\mathrm{E}} \mathrm{NO}$ was not used to guide clinical treatment.

\section{Statistical methods}

In our previous studies ${ }^{13} 14$ we noted that $>60 \%$ of patients with clinically stable moderate-severe asthma had significantly increased peripheral lung $\mathrm{C}_{\mathrm{ANO}}$ without correction for $\mathrm{NO}$ axial back-diffusion $^{22}$ and, after re-examination, $>30 \%$ after 
correction. ${ }^{13}$ In the current study, we needed to evaluate a minimum of 15 patients with moderate-severe asthma at baseline and during exacerbation to achieve $80 \%$ power to detect $a \geq 30 \%$ incidence of increased peripheral $C_{\text {ANO }}$ after correction for $\mathrm{NO}$ axial back-diffusion. ${ }^{22}$ Forty normal age-matched subjects were compared with patients with asthma at baseline using twogroup unpaired t tests. Data for those with asthma were initially analysed to determine normality distribution using ShapiroWilks test. Because of non-parametric data, analysis of variance (ANOVA) using ranks with repeated measurement was used, with clinical status including stable baseline, exacerbation and recovery as the within factor. Paired t test was used to compare change in clinical status within the same group. S+version for Windows was used for analysis (Tibco Software. Palo Alto, California, USA). Values for $\mathrm{p}<0.05$ were considered significant.

\section{RESULTS}

\section{Baseline studies}

We prospectively studied 15 (8 males) patients with moderate - severe asthma, age $57 \pm 13$ years (mean \pm SD) who had been treated with inhaled combination ICS+LABA for 3.6 \pm 0.4 years. Results of lung function studies in normal subjects and those with asthma before and $15 \mathrm{~min}$ after $180 \mu \mathrm{g}$ of albuterol by MDI are presented in table 1 . Those with asthma had baseline vital capacity of $3.0 \pm 1.0$ litres $(87 \pm 29 \%$ predicted), total lung capacity $5.8 \pm 0.9$ litres $(108 \pm 19 \%$ predicted), residual volume $2.8 \pm 1.0$ litres ( $143 \pm 47 \%$ predicted), functional residual capacity $3.5 \pm 0.9$ litres $(133 \pm 62 \%$ predicted), single breath diffusing capacity $23 \pm 6 \mathrm{ml} / \mathrm{min} / \mathrm{mm} \quad \mathrm{Hg}(98 \pm 27 \%$ predicted) and diffusing capacity/alveolar volume $5.0 \pm 0.8 \mathrm{ml} / \mathrm{min} / \mathrm{mm} \mathrm{Hg} / 1$ (126 $\pm 20 \%$ predicted). Compared with 40 age-matched normals, values for forced vital capacity (FVC), $\mathrm{FEV}_{\text {! }}$ and $\mathrm{FEV}_{1} / \mathrm{FVC}$ were significantly decreased at baseline. High-resolution, thin-section lung CT emphysema scores ${ }^{25}$ were $9 \pm 5$ (mean \pm SD), indicating none or trivial emphysema, and no bronchiectasis was noted in the 15 subjects with asthma. At baseline, serum IgE was $215 \pm 154 \mathrm{mg} / \mathrm{dl}$ and total blood eosinophil count $0.42 \pm 0.36 \times 10^{9}$ cells $/ 1$ in the 15 subjects with asthma.

\section{Baseline NO production}

Compared with age-matched normal subjects, when clinically stable, baseline values for $\mathrm{F}_{\mathrm{E}} \mathrm{NO}$ at $50 \mathrm{ml} / \mathrm{s}$, ppb ( $\left.\mathrm{p}=0.01\right), \mathrm{F}_{\mathrm{E}} \mathrm{NO}$ at $100 \mathrm{ml} / \mathrm{s}, \mathrm{ppb}(\mathrm{p}=0.005), \mathrm{J}^{\prime}$ awno, $\mathrm{nl} / \mathrm{s}(\mathrm{p}=0.02)$ and $\mathrm{C}_{\mathrm{ANO}}$, $\mathrm{ppb}$ $(p=0.04)$ in the subjects with asthma were significantly increased prior to Condorelli correction. ${ }^{22}$ The value for central airway NO flux J' awno after correction for axial back-diffusion of $\mathrm{NO}$ remained significantly increased $(p=0.02)$. However, after correcting $^{22}$ for $\mathrm{NO}$ axial back-diffusion, values for $\mathrm{C}_{\text {ANO }}$ were zero or slightly negative (not statistically different from zero) both in normal subjects and all those with asthma $(p=0.2)$, indicating no or trivial peripheral airway/alveolar $\mathrm{C}_{\mathrm{ANO}}$ concentration. Two of the 15 subjects with asthma at baseline had normal values for NO gas exchange despite abnormal spirometry (see table 1 and figures $1-5$ ).

\section{Spirometry and NO production during asthma exacerbation prior to initiation of oral corticosteroid}

During asthma exacerbation which occurred on average $101 \pm 10$ days (mean \pm SD) after baseline, there was a significant decrease in FVC and $\mathrm{FEV}_{1}$ both before and after $180 \mu \mathrm{g}$ of albuterol. During asthma exacerbation, compared with baseline, there was a significant increase in $\mathrm{F}_{\mathrm{E}} \mathrm{NO}$ production at $50 \mathrm{ml} / \mathrm{s}$ $(p=0.003)$, at $100 \mathrm{ml} / \mathrm{s}(\mathrm{p}<0.001)$ and in J' awNo $(p=0.004)$ both before and after correction $(p=0.004)$ for $\mathrm{NO}$ axial back-diffusion. There was increased $C_{\text {ANO }}$ before $(p=0.001)$, but not after $(p=0.8)$ correction for $\mathrm{NO}$ axial back-diffusion in all those with asthma. These results allowed us to reject the hypothesis that $\geq 30 \%$ of those with asthma after correction for NO axial backdiffusion would have increased $\mathrm{C}_{\mathrm{ANO}}$. Two of the subjects with asthma who had normal NO gas exchange at baseline had similar normal values during exacerbation. These two subjects had similar spirometry and serum IgE and total eosinophil count to the other 13 subjects with asthma with abnormal NO gas exchange (see table 1 and figures 1-5).

\section{Spirometry and NO production in recovery after an 8 day oral corticosteroid course}

After $10 \pm 2$ days (mean \pm SD) following initiation of an 8 day tapering course of oral prednisone, there was a significant increase in spirometry $(p \leq 0.005)$, compared with values obtained during acute exacerbation. There was also a significant decrease in $\mathrm{F}_{\mathrm{E}} \mathrm{NO}$ production at $50 \mathrm{ml} / \mathrm{s}(\mathrm{p}<0.001)$, at $100 \mathrm{ml} / \mathrm{s}$ $(p=0.001), J^{\prime}$ awNO and $C_{\text {ANO }}$ compared with values obtained during exacerbation $(p=0.01)$. Results for $\mathrm{J}_{\text {awNO }}(\mathrm{p}=0.01)$ were

Table 1 Lung function and nitrix oxide (NO) gas exchange in normal subjects and patients with asthma at baseline, during exacerbation and following recovery

\begin{tabular}{|c|c|c|c|c|}
\hline & $\begin{array}{l}\text { Normal control } \\
57 \pm 9 \text { years } n=40\end{array}$ & $\begin{array}{l}\text { Stable baseline asthma } \\
\text { F250/S50 } 57 \pm 13 \text { years } n=15\end{array}$ & $\begin{array}{l}\text { Asthma exacerbation } \\
\text { F250/S50 } n=15\end{array}$ & $\begin{array}{l}\text { Asthma recovery } F 250 / S 50 \\
\text { plus oral corticosteroid } n=15\end{array}$ \\
\hline $\begin{array}{l}\text { FVC (litres) pre/post } 180 \mu \mathrm{g} \text { of } \\
\text { albuterol }\end{array}$ & $3.6 \pm 1.0$ & $\leftrightarrow 3.2 \pm 0.9 / 3.3 \pm 0.9, \mathrm{p}=0.2$ & $\leftrightarrow 2.5 \pm 0.9 / 2.8 \pm 0.9, p=0.004 / p=0.14$ & $\leftrightarrow 3.2 \pm 0.8 / 3.2 \pm 0.7, p=0.005 / p=0.19$ \\
\hline $\mathrm{FEV}_{1}$ (litres) pre/post & $2.8 \pm 0.7$ & $2.1 \pm 0.8 / 2.2 \pm 0.8, p=0.009$ & $1.5 \pm 0.7 / 1.8 \pm 0.7, p<0.001 / p<0.001$ & $2.1 \pm 0.7 / 2.2 \pm 0.6, p<0.001 / p=0.1$ \\
\hline $\mathrm{FEV}_{1} \%$ predicted pre/post & $93 \pm 14$ & $71 \pm 23 / 78 \pm 26, p=0.004$ & $49 \pm 20 / 57 \pm 20, p<0.001 / p=0.02$ & $68 \pm 21 / 77 \pm 24, p<0.001 / p=0.02$ \\
\hline $\mathrm{FEV}_{1} / \mathrm{FVC} \%$ pre/post & $79 \pm 5$ & $66 \pm 13 / 68 \pm 14, p=0.005$ & $61 \pm 13 / 64 \pm 13, p=0.06 / p=0.4$ & $70 \pm 12 / 70 \pm 12, p=0.07 / p=0.2$ \\
\hline Large airway NO (nl/s) & $1.0 \pm 0.6$ & $1.7 \pm 1.1 p=0.02$ & $4.2 \pm 2.8 p=0.004$ & $2.0 \pm 1.0 p=0.01$ \\
\hline Large airway NO (nl/s) corrected & $1.7 \pm 1.0$ & $3.0 \pm 1.8 p=0.02$ & $7.2 \pm 4.8 p=0.004$ & $3.4 \pm 1.7 p=0.01$ \\
\hline Small airway/alveolar NO (ppb) & $3.9 \pm 2.4$ & $5.6 \pm 3.0 p=0.04$ & $11 \pm 6 p=0.001$ & $5.9 \pm 2.2 p=0.01$ \\
\hline $\begin{array}{l}\text { Small airway/alveolar NO (ppb) } \\
\text { corrected }\end{array}$ & $1.9 \pm 2.3$ & $2.2 \pm 2.7 p=0.2$ & $2.6 \pm 4.3 p=0.8$ & $1.9 \pm 2.4 p=0.4$ \\
\hline Statistical comparison & & $\begin{array}{l}\text { Baseline asthma vs } \\
\text { age-matched normals }\end{array}$ & $\begin{array}{l}\text { Exacerbation vs stable } \\
\text { asthma }\end{array}$ & Recovery vs exacerbation \\
\hline
\end{tabular}

Lung function and NO results are mean \pm SD. Measurements of NO gas exchange were obtained prior to spirometry. Spirometry obtained in patients with asthma are before and after $180 \mu \mathrm{g}$ of albuterol by metered dose inhaler. Corrected indicates the NO gas exchange values in this table have been corrected for axial NO back-diffusion. ${ }^{22}$

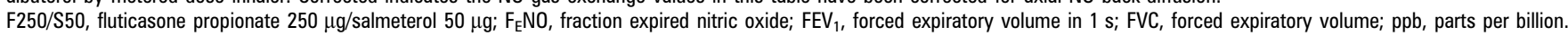




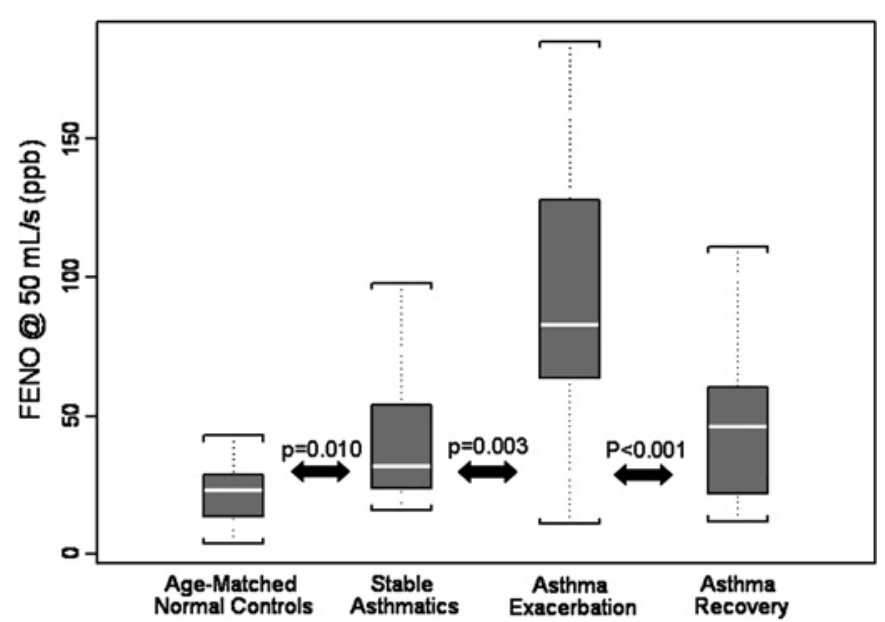

Figure 1 Measurement of total exhaled nitric oxide $\left(\mathrm{F}_{\mathrm{E}} \mathrm{NO}\right)$ at $50 \mathrm{ml} / \mathrm{s}$ in age-matched normal subjects and patients with asthma on fluticasone $250 \mu \mathrm{g} / \mathrm{salmeterol} 50 \mu \mathrm{g}$ when stable at baseline, during exacerbation and following recovery. ppb, parts per billion. Each figure notes the median, 1-3 interquartile with 5-95\% bars in normal subjects and those with asthma, and asthma outliers are represented by a line.

unchanged after correction for $\mathrm{NO}$ axial back-diffusion. However, $\mathrm{C}_{\text {ANO }}$ was significantly decreased before $(\mathrm{p}=0.01)$ but not after $(p=0.4)$ correction for $\mathrm{NO}$ axial back-diffusion. The two subjects with asthma who had normal values for $\mathrm{NO}$ gas exchange at baseline and despite exacerbation also had normal values during recovery after oral corticosteroid. Their response to oral corticosteroid was similar to that of those with asthma with elevated NO gas exchange (see table 1 and figures $1-5$ ).

\section{DISCUSSION}

Spirometry and exhaled $\mathrm{NO}$ at multiple expiratory flow rates were measured to determine the contribution of central and peripheral airway/alveolar NO production sites using the twocompartment model. ${ }^{11}$ Data were obtained initially at baseline, during asthma exacerbation prior to initiating oral corticosteroid, and subsequently during recovery immediately following an 8 day course of tapering oral corticosteroid. At baseline, despite optimal clinical stability, there was significantly

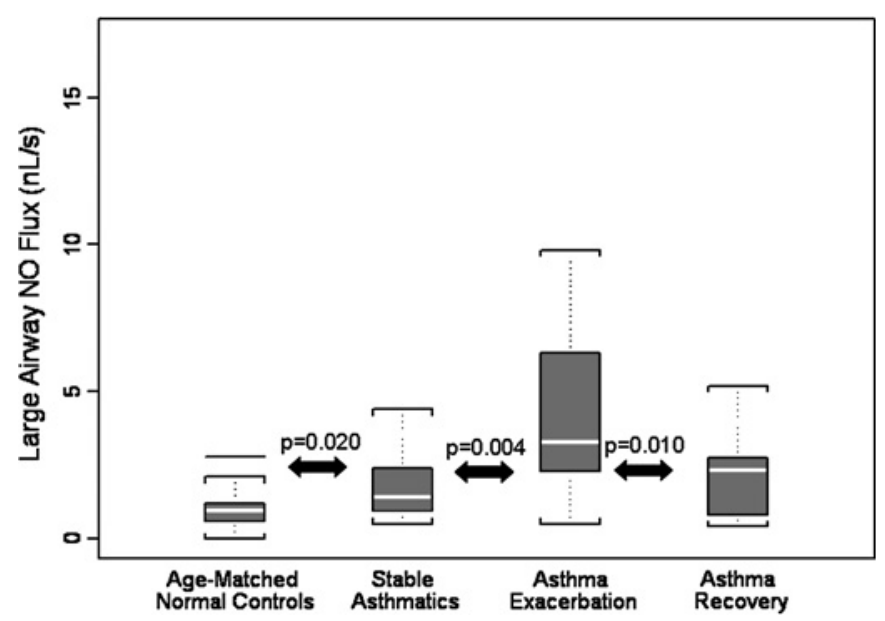

Figure 2 Measurement of large/central airway nitric oxide (NO) flux $(\mathrm{nl} / \mathrm{s})$ in age-matched normal subjects and patients with asthma on fluticasone $250 \mu \mathrm{g} / \mathrm{salmeterol} 50 \mu \mathrm{g}$ when stable at baseline, during exacerbation and following recovery. NO values are uncorrected for axial back-diffusion. $^{22}$

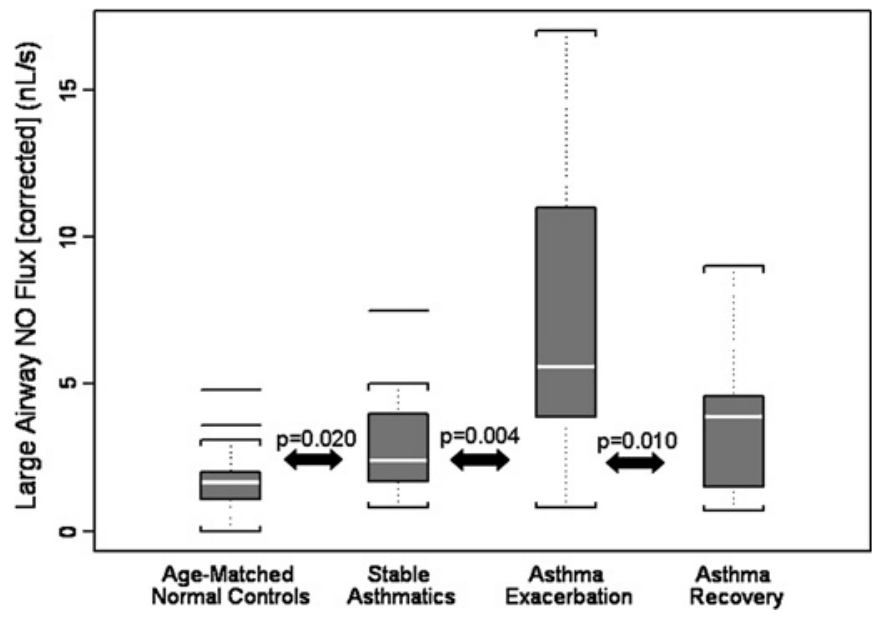

Figure 3 Measurement of large/central airway nitric oxide (NO) flux $(\mathrm{nl} / \mathrm{s})$ adjusted for axial NO back-diffusion ${ }^{22}$ in age-matched normal subjects and patients with asthma on fluticasone $250 \mu \mathrm{g} / \mathrm{salmeterol}$ $50 \mu \mathrm{g}$ when stable at baseline, during exacerbation and following recovery.

abnormal spirometry and both increased central airway NO flux and peripheral airway/alveolar $\mathrm{C}_{\mathrm{ANO}}$ before correction for $\mathrm{NO}$ axial back-diffusion. ${ }^{22}$ However, after correction, peripheral airway/alveolar $\mathrm{C}_{\mathrm{ANO}}$ was normal compared with 40 agematched healthy, non-smoking controls with normal lung function. During asthma exacerbation, with greater expiratory airflow limitation, central airway NO flux, (J'awnO) was increased before and after correction for $\mathrm{NO}$ axial back-diffusion. $^{12}{ }^{22}$ However, peripheral airway/alveolar $\mathrm{C}_{\mathrm{ANO}}$ was significantly increased before but not after correction for $\mathrm{NO}$ axial back-diffusion. ${ }^{12} 22$ The results suggest that central airways are the predominant site of increased $\mathrm{NO}$ gas exchange in 13 of 15 patients with asthma with moderate-severe expiratory airflow limitation studied at baseline and following exacerbation. Two of the 15 studied patients with asthma had normal values for $\mathrm{NO}$ gas exchange at baseline, during exacerbation and following recovery after oral corticosteroid. These two patients may have a non-eosinophilic-mediated inflammatory pathway. However, their clinical and physiological response to 8 day tapering oral corticosteroid treatment was similar to that of the

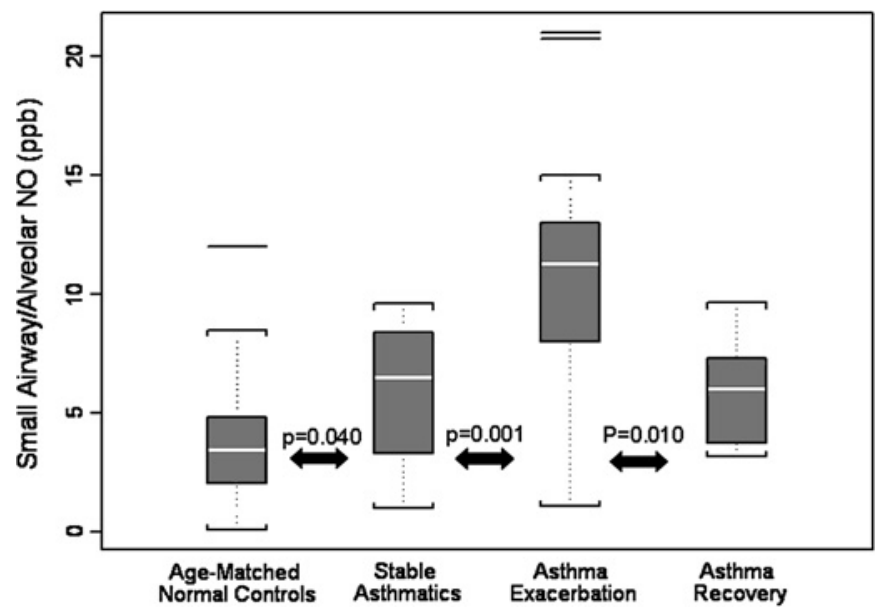

Figure 4 Measurement of small and peripheral airway/alveoli $C_{\text {ANO }}$ $(\mathrm{ppb})$ in age-matched normals subjects and patients with asthma on fluticasone $250 \mu \mathrm{g} / \mathrm{salmeterol} 50 \mu \mathrm{g}$ when stable at baseline, during exacerbation and following recovery. Nitric oxide (NO) values are uncorrected for axial back-diffusion. ${ }^{22}$ 


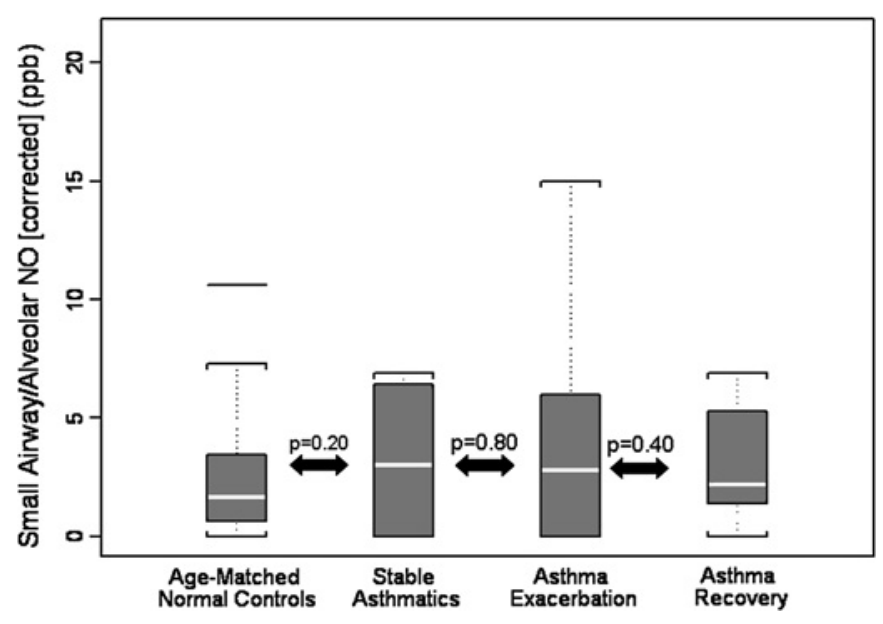

Figure 5 Measurement of small and peripheral airway/alveoli $C_{\text {ANo }}$ (ppb) adjusted for nitric oxide (NO) axial back-diffusion ${ }^{22}$ in age-matched normal subjects and patients with asthma on fluticasone $250 \mu \mathrm{g} /$ salmeterol $50 \mu \mathrm{g}$ when stable at baseline, during exacerbation and following recovery.

other 13 subjects with asthma, with increased central airway $\mathrm{J}_{\text {awNO }}$ flux. Furthermore, measurement of $\mathrm{F}_{\mathrm{E}} \mathrm{NO}$ at $50 \mathrm{ml} / \mathrm{s}$, which reflects predominantly large airway NO flux, may be both more relevant and practical, especially when peripheral airway/ alveolar NO is normal.

\section{Peripheral airway/alveolar NO production and inhaled corticosteroid}

It has been reported that increased central airway NO flux and peripheral lung $\mathrm{C}_{\mathrm{ANO}}$ in asthma reflects predominantly eosinophilic-mediated inflammatory pathways, presumably stimulated by upregulated or overexpressed inducible nitric oxide synthase (iNOS), or less probably constitutive nitric oxide synthase (cNOS). ${ }^{1-6}$ The present study contradicts in part our previous observations ${ }^{13} 14$ of increased peripheral lung $C_{\text {ANO }}$ in $60 \%$ of clinically stable patients with moderate-severe asthma that did not take into account axial NO back-diffusion. ${ }^{22}$ Upon re-examination of our original data, ${ }^{13} 14$ and after correcting for axial NO back-diffusion, ${ }^{22}$ peripheral $\mathrm{C}_{\text {ANO }}$ still remained increased in $30 \%$ of those with asthma. ${ }^{13}$ The discrepancy with the present results may in part be related to different cohorts of patients with asthma and the therapeutic regimen. Previous studies uncorrected for axial NO back-diffusion ${ }^{12} 22$ noted increased central airway NO flux and increased peripheral airway/alveolar $\mathrm{C}_{\mathrm{ANO}}$ in those with clinically stable asthma with mild ${ }^{15}$ 18-21 and moderate-severe obstruction ${ }^{13} 141617$ despite ICS. Review of published data from van Veen et al ${ }^{16}$ suggests normal peripheral $\mathrm{C}_{\mathrm{ANO}}$ production after we corrected for NO axial back-diffusion. ${ }^{22}$ Alternatively, previously published results, also without correction for axial NO backdiffusion, ${ }^{12} 22$ by Hogman et al, ${ }^{8}$ Brindicci et a ${ }^{20}$ and Shin et al, ${ }^{21}$ reported increased central $\mathrm{NO}$ flux but normal peripheral $\mathrm{C}_{\mathrm{ANO}}$ in clinically stable patients with asthmat with mild ${ }^{21}$ and moderate-severe ${ }^{80}$ expiratory airflow limitation despite ICS. Kerckx and Van Muylem ${ }^{12}$ noted normal peripheral airway/ alveolar NO concentration in those with mild asthma after correction for $\mathrm{NO}$ axial back-diffusion. However, Brindicci et $a^{20}$ reported increased $\mathrm{C}_{\mathrm{ANO}}$ during exacerbation in those with moderate-severe asthma. However, re-examination of their published data ${ }^{20}$ suggests normal $\mathrm{C}_{\mathrm{ANO}}$ after correction for $\mathrm{NO}$ back-diffusion. The reduction in $\mathrm{C}_{\mathrm{ANO}}$ following oral corticosteroid in the present study is similar to our previous experi- ence $^{13}$ and that of Berry et a $l^{17}$ in those with clinically stable asthma prior to correction for $\mathrm{NO}$ axial back-diffusion. We favour the new hypothesis that $<30 \%$ of those with moderate-severe asthma at baseline and after exacerbation have increased $C_{\text {ANO }}(p<0.001)$ with a $95 \%$ upper confidence limit for incidence of increased $C_{\text {ANO }}$ of $22 \%$. We would have to study 15 additional subjects with asthma to achieve a $95 \%$ upper confidence limit for an incidence of increased $C_{\mathrm{ANO}}<10 \%(p<0.001)$.

\section{Potential mechanism(s) for peripheral NO before and after correction for axial NO diffusion}

Previously, Silkoff et al reported that methacholine-induced bronchoconstriction in subjects with asthma, with reduction in epithelial surface area, decreased NO production by $\sim 15 \%$. The partial pressure of $\mathrm{NO}$ in the small airway and alveolar area $\left(\mathrm{P}_{\mathrm{LNO}}\right)$ is equal to the production of $\mathrm{NO}$ by surrounding tissue $\left(\mathrm{V}_{\mathrm{NO}}\right)$ /diffusing capacity of $\mathrm{NO}$ from air space into surrounding blood vessels $\left(\mathrm{D}_{\mathrm{LNO}}\right){ }^{26}$ Therefore, either an increase in NO tissue production as an inflammatory response (increased iNOS and/or cNOS) or reduced $\mathrm{D}_{\mathrm{LNO}}$, or both could account for increased $\mathrm{P}_{\mathrm{LNO}}{ }^{26}$ Lehtimaki et al ${ }^{25}$ have previously shown an inverse relationship between $\mathrm{C}_{\mathrm{ANO}}$ and pulmonary capillary diffusing capacity in alveolitis. In asthma, we ${ }^{13} 14$ have previously noted that the increase in $\mathrm{C}_{\mathrm{ANO}}$ was attributed to an increase in NO tissue production, probably related to increased iNOS, and suspect that this is also operant during asthma exacerbation since reduction in $\mathrm{D}_{\mathrm{LNO}}$ in asthma is unlikely. Furthermore, it would have a relevant effect on $\mathrm{NO}$ axial backdiffusion. The increase if any in peripheral lung $\mathrm{C}_{\mathrm{ANO}}$ in clinically stable patients with asthma is modestly downregulated by inhaled compared with systemic corticosteroids. ${ }^{13} 1417$

The original two-compartment model developed by Tsoukias and George et al ${ }^{11}$ to describe central and peripheral airway/ alveolar site of $\mathrm{NO}$ concentration failed to account for axial backdiffusion of NO from the central airways towards the alveoli. This error may have led to underestimation of central airway NO flux and overestimation of peripheral/alveolar $\mathrm{C}_{\mathrm{ANO}}$. Subsequent contributions from Condorelli et a ${ }^{22}$ for $\mathrm{NO}$ axial back-diffusion estimated that large airway NO flux is 1.7 -fold greater if the flow range is between 50 and $250 \mathrm{ml} / \mathrm{s}$, with trivial NO levels in peripheral lung units in normal subjects (approaching zero). The negligible level of $\mathrm{C}_{\mathrm{ANO}}$ in normal subjects is probably due to the great affinity between periacinar $\mathrm{NO}$ and the haemoglobin molecule in the surrounding blood pool. ${ }^{7} 111222$

Important experimental observations by Kerckx and Van Muylem ${ }^{27}$ have also demonstrated the inhomogeneous distribution of NO production in healthy adults, with the majority of exhaled NO coming from very proximal airways and 'larger' peripheral airways of $<17$ generation, with little contribution from the lung periphery after correcting for axial NO backdiffusion. The response following histamine-induced bronchoconstriction in normal subjects has been studied by Verbanck et $a l^{28}$ who noted its potential effect to increase convective flow of $\mathrm{NO}$ and $\mathrm{FeNO}$ at $50 \mathrm{ml} / \mathrm{s}$ by a paradoxical decrease in axial back-diffusion of NO. Additionally, Kerckx et al ${ }^{12}$ reported the inhomogeneous airway contribution of $\mathrm{NO}$ production in those with stable asthma without expiratory airflow obstruction and noted a minimal peripheral contribution of $\mathrm{NO}$ production, similar to normal subjects, after correcting for axial NO backdiffusion. These observations are similar to those noted by Condorelli et $\mathrm{al}^{22}$ and reinforce the present observations in those with asthma with abnormal expiratory airflow limitation. It is possible that during an acute asthma exacerbation, the correction factor for axial NO back-diffusion would be smaller, due to 
a smaller cross-sectional area available for back-diffusion of $\mathrm{NO}$ through constricted airways. This would result in a potential underestimation of $\mathrm{C}_{\mathrm{ANO}}$ and overestimation of J' awNO using the current technique and interpretation. There are currently no experimental data available on back-diffusion of $\mathrm{NO}$ during acute asthma.

\section{Large airway NO flux and ICS, and potential mechanism(s)}

Central airway NO flux is the product of $\mathrm{NO}$ production in bronchial wall mucosa $\left(\mathrm{C}_{\mathrm{w}}\right)$ and bronchial $\mathrm{NO}$ diffusing capacity $\left(\mathrm{D}_{\mathrm{awNO}}\right)$ which reflects transfer of $\mathrm{NO}$ from the airway wall to the lumen of expired air and is proportional to the lumen surface area and transfer coefficient. ${ }^{10}{ }^{26}$ While we did not measure $C_{w}$ and $\mathrm{D}_{\text {awNO, this could be estimated as noted by Silkoff et al }}{ }^{10}$ using low exhaled flow rates $(5-10 \mathrm{ml} / \mathrm{s})$ and application of a non-linear method. We suspect that in those with both clinically stable and unstable asthma moderate dose ICS (F250/S50) is probably unable significantly to suppress increased bronchoreactive iNOS and/or resident cNOS in the larger airways to reduce bronchial wall $\left(\mathrm{C}_{\mathrm{w}}\right) \mathrm{NO}$ production effectively. Review of the individual data in the present study indicates that 2 of the 15 studied subjects with asthma had normal baseline values for large and small airway/alveolar $\mathrm{C}_{\mathrm{ANO}}$ and without subsequent increase during exacerbation. Despite lack of induced sputum and or airway cellular analyses, this implies a non-eosinophilic inflammatory-mediated pathway ${ }^{29}{ }^{30}$ In summary, in the present asthma cohort, and after correction for $\mathrm{NO}$ axial backdiffusion, the central airways remain the predominant site of increased $\mathrm{NO}$ gas exchange in the subjects with asthma studied at baseline, following exacerbation and subsequent recovery.

\section{Clinical implications}

Several investigators ${ }^{2}{ }^{31-36}$ have addressed the clinical role of add-on monitoring of exhaled $\mathrm{NO}$ at a single expiratory airflow rate, usually at $50 \mathrm{ml} / \mathrm{s}$, to help guide inhaled and or systemic corticosteroid dosing in those with clinically stable and unstable asthma, in addition to guideline recommendations which include spirometry. ${ }^{31}$ Results of five double-blind randomised control trials ${ }^{32-36}$ comparing add-on $\mathrm{F}_{\mathrm{E}} \mathrm{NO}$ versus usual guidelines including spirometry ${ }^{31}$ were only equivocal. This suggests that routine serial measurements of $\mathrm{F}_{\mathrm{E}} \mathrm{NO}$ for clinical asthma management does not appear necessary. However, multiple issues related to study design question the validity of the conclusions. ${ }^{37}$ The present study is an extension of our original investigation ${ }^{13} 14$ to define and partition central and peripheral airway/alveolar sites of $\mathrm{NO}$ concentration in those with stable asthma at baseline and during exacerbation, initially without ${ }^{13} 14$ and now with correction for $\mathrm{NO}$ axial back-diffusion. ${ }^{12} 22$ This requires measuring $\mathrm{NO}$ gas exchange at four separate expiratory flow rates. However, the current results suggest predominantly central airway sites of abnormal $\mathrm{NO}$ gas exchange, presumably reflective of eosinophilic-mediated inflammation, in 13 of the 15 studied subjects with asthma. While measuring $\mathrm{F}_{\mathrm{E}} \mathrm{NO}$ at a single expiratory flow rate at $50 \mathrm{ml} / \mathrm{s}$ does not provide any information about the contribution of $\mathrm{C}_{\mathrm{ANO}}$ in peripheral sites, it appears that $\mathrm{NO}$ overproduction in asthma can be localised to the central airways. Furthermore, it should be emphasised that increased $\mathrm{F}_{\mathrm{E}} \mathrm{NO}$ at $50 \mathrm{ml} / \mathrm{s}$, a surrogate of central airway increased $\mathrm{NO}$ flux, correlates only modestly with induced sputa eosinophilia $>3 \%: r^{2}=0.26, p<0.001$ with a sensitivity of $71 \%$ and specificity of $72 \%,{ }^{37}$ and $r^{2}=0.29, p=0.007$ with tissue eosinophilia in treated subjects with severe refractory asthma. ${ }^{5}$ The current asthma results are in contrast to our observations in chronic obstructive pulmonary disease where both large airway and peripheral NO are normal, yet large airway NO flux was suppressed with moderate but not low dose ICS. ${ }^{38}$

\section{SUMMARY}

We used the two-compartment $\mathrm{NO}$ model $^{11}$ with correction ${ }^{22}$ for axial back-diffusion of $\mathrm{NO}$ to avoid spurious underestimation of large airway $\mathrm{NO}$ flux and overestimation of peripheral $\mathrm{C}_{\mathrm{ANO}}$. In 13 of 15 the studied clinically stable adult subjects, there was increased NO flux in predominantly central airway sites in those with moderate-severe asthma at baseline with abnormal spirometry despite inhaled corticosteroid. NO production in central airway sites was further increased in the same 13 patients during asthma exacerbation prior to oral corticosteroid and decreased following an 8 day course of tapering oral corticosteroid. This suggests ongoing eosinophilic-mediated inflammation in central airways in these 13 subjects with asthma. Following correction for axial back-diffusion of NO, peripheral airway/ alveolar NO values were similar to those of normal subjects. These results are in contrast to our previous observations in other patients with asthma ${ }^{13} 14$ even after correction for axial NO back-diffusion, ${ }^{22}$ and suggest that peripheral $\mathrm{NO}$ concentration in those with asthma may be normal. Increased measurement of $\mathrm{F}_{\mathrm{E}} \mathrm{NO}$ at $50 \mathrm{ml} / \mathrm{s}$ may be a practical surrogate for large airway increased NO flux, especially when peripheral lung $\mathrm{C}_{\mathrm{ANO}}$ is normal as in the present asthma exacerbation study.

Competing interests PS receives royalties from patents licensed to General Electric Instruments and Aperion, both manufacturers of exhaled NO equipment (range US $\$ 2000-U S \$ 3000 / a n n u m)$. Consultant to GE Instruments, Aperion and Aperion (range US\$10 000-\$15 000/annum).

Ethics approval This study was conducted with the approval of the Lakewood Regional Medical Center, Lakewood, California, USA; Western IRB, Olympia, Washington, USA and Registered National Clinical Trials: 00576069.

Contributors AFG designed, developed and supervised this study and was responsible for all patient care and this manuscript. AK, CMS and TM were responsible for data analysis. CFT, AK and CF were responsible for all laboratory studies. SCG and PES provided invaluable input towards data interpretation and manuscript preparation. Fernando Camacho of Damos, Toronto, Ontario, Canada provided invaluable statistical help.

Provenance and peer review Not commissioned; externally peer reviewed.

\section{REFERENCES}

1. Kharitonov SA, Gonio F, Kelly C, et al. Reproducibility of exhaled nitric oxide measurements in healthy and asthmatic adults and children. Eur Respir $J$ 2003;21:433-8.

2. Green RH, Brightling CE, McKenna S, et al. Asthma exacerbations and sputum eosinophil counts: a randomized controlled trial. Lancet 2002;360:1715-21.

3. Taylor DR, Pijnenburg MW, Smith AD, et al. Exhaled nitric oxide measurements: clinical application and interpretation. Thorax 2006;61:817-27.

4. Ricciardolo FL, Sterk PJ, Gaston B, et al. Nitric oxide in health and disease of the respiratory system. Physiol Rev 2004;84:731-65.

5. Silkoff PE, Lent AM, Busacker AA, et al. Exhaled nitric oxide identifies persistent eosinophilic phenotype in severe refractory asthma. J Allergy Clin Immunol 2005;116:1249-55

6. American Thoracic Society. Recommendations for standardized procedure for the online and offline measurement of exhaled lower respiratory nitric oxide and nasal nitric oxide in adults and children. Am J Respir Crit Care Med 2005;60:2104-17.

7. George SC, Hogman M, Permutt $S$, et al. Modeling pulmonary nitric oxide exchange. J Appl Physiol 2004;96:831-9.

8. Hogman $\mathbf{M}$, Holmkvist T, Wegener T, et al. Extended nitric oxide analysis applied to patients with COPD, allergic asthma, and allergic rhinitis. Respir Med 2002:96:24-30.

9. Pietropaoli AP, Perillo IB, Torres A, et al. Simultaneous measurement of nitric oxide production by conducting and alveolar airways of humans. J Appl Physiol 1999;87:1532-42.

10. Silkoff PE, Sylvester JT, Zamel N, et al. Airway nitric oxide diffusion in asthma. Role in pulmonary function and bronchial responsiveness. Am J Respir Crit Care Med 2000;161:1218-28.

11. Tsoukias NM, George SC. A two-compartment model of pulmonary nitric oxide exchange dynamics. J Appl Physiol 1998;85:653-66.

12. Kerckx Y, Michilis A, Van Muylem A. Airway contribution to alveolar nitric oxide in healthy subjects and stable asthma patients. J Appl Physiol 2008;104:918-24. 
13. Gelb AF, Flynn-Taylor C, Nussbaum E, et al. Airway and alveolar nitric oxide inflammation in treated asthma. Am J Respir Crit Care Med 2004;170:737-41.

14. Gelb AF, Flynn Taylor C, Shinar CM, et al. Role of spirometry and exhaled nitric oxide to predict exacerbations in treated asthmatics. Chest 2006;129:1492-9.

15. Lehtimaki L, Kankaanranta H, Saarelainen S, et al. Inhaled fluticasone decreases bronchial but not alveolar nitric oxide output in asthma. Eur Respir J 2001;18:635-9.

16. vanVeen IH, Sterk PJ, Schot R, et al. Alveolar nitric oxide versus measures of peripheral airway dysfunction in severe asthma. Eur Respir J 2006;27:951-6.

17. Berry M, Hargadon B, Morgan A, et al. Alveolar nitric oxide in adults with asthma: evidence of distal lung inflammation in refractory asthma. Eur Respir $\mathrm{J}$ 2005;25:986-91.

18. Mahut B, Delacourt C, Zerah- Lancner F, et al. Increase in alveolar nitric oxide in the presence of symptoms in childhood asthma. Chest 2004;125:1012-18.

19. Paraskakis E, Brindicci C, Fleming L, et al. Measurement of bronchial and alveolar nitric oxide production in normal children and children with asthma. Am J Respir Crit Care Med 2006;174:260-67.

20. Brindicci C, Ito K, Barnes PJ, Kharitonov SA. Differential flow analysis of exhaled nitric oxide in patients with asthma of differing severity. Chest 2007;131:1353-62.

21. Shin HW, Rose-Gottron CM, Cooper DM, et al. Airway diffusing capacity of nitric oxide and steroid therapy in asthma. J Appl Physiol 2004:96:65-75.

22. Condorelli $\mathbf{P}$, Shin HW, Aledia AS, et al. A simple technique to characterize proximal and peripheral nitric oxide exchange using constant flow exhalations and axial diffusion model. J Appl Physiol 2007:102:417-25.

23. Silkoff PE, McClean PA, Slutsky AS, et al. Marked flow-dependence of exhaled nitric oxide using a new technique to exclude nasal nitric oxide. Am J Resp Crit Care Med 1997;155:260-7.

24. Gelb AF, Hogg JC, Muller NL, et al. Contribution of emphysema and small airways in COPD. Chest 1996;109:353-9.

25. Lehtimaki L, Kankaanranta H, Saarelainen S, et al. Extended exhaled NO measurement differentiates between alveolar and bronchial inflammation. Am J Resp Crit Care Med 2001;163:1557-61
26. Hyde RW, Geigel EJ, Olszowaka AJ, et al. Determination of production of nitric oxide by lower airways of humans-theory. J Appl Physiol 1997;82:1290-6.

27. Kerckx Y, Van Muylem A. Axial distribution heterogeneity of nitric oxide airway production in healthy adults. J App/ Physiol 2009:106:1832-9.

28. Verbanck S, Kerckx Y, Schuermans D, et al. Effect of airways constriction on exhaled nitric oxide. J Appl Physiol 2008;104:909-11.

29. Wenzel SE, Schwartz LB, Langmack EL, et al. Evidence that severe asthma can be divided pathologically into two inflammatory subtypes with distinct physiologic and clinical characteristics. Am J Respir Crit Care Med 1999:160:1001-8.

30. Haldar P, Pavord ID. Noneosinophilic asthma: a distinct clinical and pathologic phenotype. J Allergy Clin Immunol 2007;119:1043-52.

31. Global strategy for asthma management and prevention. http://www.ginasthma.org

32. Szefler SJ, Mitchall H, Sorkness CA, et al. Management of asthma based on exhaled nitric oxide in addition to guideline-based treatment for inner-city adolescents and young adults: a randomized controlled trial. Lancet 2008:372:1065-72.

33. de Jongste JC, Carraro S, Hop WC, et al. Daily telemonitoring of exhaled nitric oxide and symptoms in the treatment of childhood asthma. Am J Respir Crit Care Med 2008;179:93-7.

34. Shaw DE, Berry MA, Thomas M, et al. The use of exhaled nitric oxide to guide asthma management: a randomized controlled trial. Am J Respir Crit Care Med 2007; 176:231-7

35. Pijnenburg MW, Bakker EM, Hop WC, et al. Titrating steroids on exhaled nitric oxide in children with asthma: a randomized controlled trial. Am J Respir Crit Care Med 2005;172:831-6.

36. Smith AD, Cowan JO, Brassett KP, et al. Use of exhaled nitric oxide measurements to guide treatment in chronic asthma. N Engl J Med 2005;352:2163-73.

37. Berry MA, Shaw DE, Green $\mathrm{RH}$, et al. The use of exhaled nitric oxide concentration to identify eosinophilic airway inflammation: an observational study in adults with asthma. Clin Exp Allergy 2005;35:1175-9.

38. Gelb AF, Taylor CF, Krishnan A, et al. Central and peripheral airway sites of nitric oxide gas exchange in COPD. Chest 2010;137:575-84.

\section{Lung alert}

\section{Non-invasive ventilation (NIV) immediately after extubation reduces ventilatory failure and 90 -day mortality in patients with hypercapnia}

This randomised open controlled trial took place from 2005-7 in three Spanish intensive care units. The aim was to assess whether non-invasive ventilation (NIV) would prevent respiratory failure and hence re-intubation, an independent risk factor for mortality, nosocomial pneumonia and length of hospital stay in patients who developed hypercapnia (arterial carbon dioxide tension $>45 \mathrm{~mm} \mathrm{Hg}$ ) during a spontaneous breathing trial prior to extubation. The secondary end point was 90-day mortality.

One hundred and sixty-four consecutive patients were registered and 106 underwent randomisation. Fifty-four were assigned NIV (mean pressure $17 / 4 \mathrm{~cm} \mathrm{H}_{2} \mathrm{O}$ ) immediately after extubation for a maximum of $24 \mathrm{~h}$ while the control group was given oxygen alone. Both groups were monitored for ventilatory failure and, if found, were either managed with reintubation or rescue NIV according to predefined criteria.

Statistically significant differences in the development of respiratory failure were found in the NIV group compared with the controls (15\% vs $48 \%$ ), the impact occurring within the first $24 \mathrm{~h}$. There was, however, no difference in the rate of re-intubation or in the length of stay in hospital or in the intensive care unit (ICU). This may have been a result of rescue NIV being deployed in both groups; $20 / 25$ controls in respiratory failure met the criteria for rescue NIV, leading to $75 \%$ avoiding re-intubation, a better outcome than in previous reports.

Although overall mortality in the ICU and hospital did not differ, 90-day mortality was significantly reduced in the NIV group, suggesting longer term benefits of NIV which cannot be explained by re-intubation avoidance alone and warrants further assessment.

- Ferrer M, Sellares J, Valencia M, et al. Non-invasive ventilation after extubation in hypercapnic patients with chronic respiratory disorders: randomised controlled trial. Lancet 2009;374:1082-8.

\section{Stone}

The Royal London Hospital, London, UK

Correspondence to Dr I Stone, The Royal London Hospital, Whitechapel, London E1 1BB, UK; ian.stone@bartsandthelondon.nhs.uk

Thorax 2010;65:625. doi:10.1136/thx.2010.141077 